\title{
Polymerized Type I Collagen Reverts Airway Hyperresponsiveness and Fibrosis in a Guinea Pig Asthma Model
}

\author{
Blanca Bazán-Perkins ${ }^{1}$, Maria G. Campos² \\ and Edgar Sánchez-Guerrero ${ }^{1}$ \\ ${ }^{1}$ Instituto Nacional de Enfermedades Respiratorias, \\ 2Instituto Mexicano del Seguro Social, \\ México
}

\section{Introduction}

Asthma is a chronic, heterogeneous and variable disease in which airways inflammation, transient obstruction and hyperresponsiveness are the major features of the illness (Faffe, 2008; Jenkins et al., 2005; Lemanske \& Busse, 2010; Sugita et al., 2003). The inflammation in asthma is characterized by eosinophil cell infiltration although neutrophils are also observed in acute asthma exacerbation and in severe asthma patients (Fahy, 2009; Kim \& Rhee, 2010; Venge, 2010). A main role of eosinophils and neutrophils in asthma is to release mediators involved in the development of airway pathological structural changes, the called airway remodeling. An important consequence of airway remodeling is the thickening of the airway wall produced by the deposit of extracellular matrix components (Bazan-Perkins et al., 2009; Janson, 2010; Salerno et al., 2009). The enlargement of airway wall could alter the transient airway obstruction in asthma that usually is resolved either spontaneously or after treatment, by inducing a residual and permanent airway obstruction (Broekema et al., 2011; Janson, 2010; Jeffery et al., 2000; Wenzel, 2003).

Airway hyperresponsiveness is a crucial physiopathological feature of asthma fundamentally because maintains a relation to the disease magnitude (Busse, 2010; Cockcroft \& Davis, 2006; O'Byrne \& Inman, 2003; Sugita et al., 2003). Although the mechanism involved in the generation of airway hyperresponsiveness is not attributable to a single but to multiple pathological processes, two main factors could contribute to its development: inflammation and remodeling. In this scenario, it has been observed that the inflammatory factor is associated to inducible, transient and variable hyperresponsiveness while remodeling has been related to persistent airway hyperresponsiveness (Busse, 2010; Cockcroft \& Davis, 2006; O'Byrne \& Inman, 2003). Additionally, variable hyperresponsiveness occurs mainly in acute asthma while persistent hyperresponsiveness predominantly takes place in chronic or severe asthma (Cockcroft \& Davis, 2006; O'Byrne \& Inman, 2003; Wenzel, 2003). Nevertheless, independently of its pathological basis, the development of therapeutic strategies reducing the hyperresponsiveness is fundamental in asthma control.

Polymerized type I collagen (PtI-collagen) is a composite made with a $\gamma$-irradiated mixture of atelopeptidic porcine type I dermal collagen and polyvinylpyrrolidone that has shown 
anti-inflammatory and fibrolytic properties in many diseases. In humans, PtI-collagen is safe, well-tolerated and non-genotoxic, as shown in short and long administration periods (Furuzawa-Carballeda et al., 2003). PtI-collagen effects has been evaluated in rheumatoid arthritis patients (Furuzawa-Carballeda et al., 1999; Furuzawa-Carballeda et al., 2003; Furuzawa-Carballeda et al., 2006; Furuzawa-Carballeda et al., 2002), skin diseases as scleroderma (Furuzawa-Carballeda et al., 2005), pressure ulcers (Zeron et al., 2007) and hypertrophic scars (Krotzsch-Gomez et al., 1998), and a case of its use in ileocolonic ulcer has also been reported (De Hoyos Garza et al., 2007).

In bone fracture in rats, PtI-collagen stimulates the healing process and accelerates the new bone formation (Chimal-Monroy et al., 1998; Furuzawa-Carballeda et al., 2003). Furthermore, in neoformed bone tissue in dogs, favored the vascular growth and the expression of transforming growth factor- $\beta 1$ (Ascencio et al., 2004). After appendectomy in rabbits, decreases the incidence and size of intra-abdominal adhesions (Cervantes-Sanchez et al., 2003). Moreover, in the tracheoplasty site in dogs, reduces the inflammatory lymphocytic infiltration and the degree of fibrosis and tracheal stenosis (Olmos-Zuniga et al., 2007). In addition, in rat chronic cyclosporine nephropathy model, PtI-collagen has shown anti-apoptotic properties (Sanchez-Pozos et al., 2010).

In guinea pigs we have observed that PtI-collagen administrated in acute asthma model reduces the expression of TNF in addition to airway eosinophil and neutrophil infiltration, as well as fibrosis (Moreno-Alvarez et al., 2010). In this study we have evaluated the effects of PtI-collagen in a guinea pig allergic-asthma model with remodeled airways and antigeninduced airway hyperresponsiveness (AI-AHR) to histamine.

\section{Materials and methods}

We used healthy male guinea pigs (350-400 g) purchased originally from Harlan Mexico (strain HsdPoc:DH) and reproduced at our institutional laboratory animal facilities. Animals were bred in filtered air-conditioned, $12 / 12$-h light/dark cycles, at $21 \pm 1^{\circ} \mathrm{C}$ and $50-70 \%$ humidity, and fed with sterilized pellets (2040 Harlan Teklad Guinea Pig Diet) and water ad libitum. The protocol was reviewed and approved by the Scientific and Bioethics Committees of the Instituto Nacional de Enfermedades Respiratorias Ismael Cosio Villegas in Mexico City.

\subsection{Study design}

After an initial sensitization protocol, guinea pigs were intermittently exposed to the aerosolized allergen (ovalbumin, OVA) for up to 125 days (asthma model group), receiving a total of twelve allergenic challenges (Fig. 1). The control group animals received saline solution instead OVA. Some animals from both asthma model and control groups were treated with $0.66 \mathrm{mg} / \mathrm{ml}$ of PtI-collagen aerosols administrated every 5 days from day 65 to day 120. The development of AI-AHR was evaluated in every guinea pig group by performing dose-response curves to histamine before and after either the antigen or saline in the reinforcement day (day 8) and at the sixth and twelfth antigenic or saline challenges. After the twelfth antigenic or saline challenges, animals were euthanized and a bronchoalveolar lavage was carried out to analyze cell count. Then, lung samples were obtained to analyze both the changes in the amount of collagen stain in subepithelial mucosa by Masson trichrome by light microscopy. Airway subepithelial mucosa was defined as the area comprised between the basal edge of epithelial cells and the beginning of 
airway smooth muscle, a region containing mainly basement membrane and lamina propria.

\subsection{Sensitization procedure}

On the first day, each guinea pig received a single intraperitoneal injection of OVA (0.06 $\mathrm{mg} / \mathrm{ml}$, Sigma St Louis, EU) with aluminium hydroxide $(1 \mathrm{mg} / \mathrm{ml}$; J.T. Baker, NJ, EU) dispersed in saline solution (Fig. 1). Sensitization was reinforced 8 days later with OVA aerosols $(3 \mathrm{mg} / \mathrm{ml}$ saline) delivered during $5 \mathrm{~min}$. Aerosols were produced by an US-1 Bennett nebulizer (flow, $2 \mathrm{ml} / \mathrm{min}$ ), releasing mixed particles, $44 \%<4 \mu \mathrm{m}$ in size, $38 \%$ of 4 $10 \mu \mathrm{m}$, and $18 \%>10 \mu \mathrm{m}$ (multistage liquid impinger, Burkard Manufacturing Co., Rickmansworth, Hertfordshire, UK). From day 15 onward, guinea pigs were challenged every 10 days with OVA aerosols $(1 \mathrm{mg} / \mathrm{ml}$ in the first challenge, and $0.5 \mathrm{mg} / \mathrm{ml}$ in the eleven subsequent challenges) during $1 \mathrm{~min}$. Control guinea pigs received inhalatory challenges with vehicle (saline solution). All challenges were carried out while the guinea pig was inside a barometric plethysmograph, allowing us to record acute bronchoobstructive response to the antigenic challenge immediately after OVA delivery was ended, as described in the following section. This guinea pig model of allergic asthma does not develop a noticeable late airway response. We corroborated that this sensitization procedure induces production of OVA-specific IgG1 and IgE.

\subsection{Barometric plethysmography}

Whole-body single-chamber plethysmography for freely moving animals (Buxco Electronics Inc., Troy, NY, USA) was used to evaluate the pulmonary function indirectly according to principles previously described (Hamelmann et al., 1997; Vargas et al., 2010). Briefly, pressure inside the plethysmograph was measured through a differential transducer connected to a preamplifier. Because air in lungs is heated and humidified, during the inspiratory phase the volume of air inside the thorax is larger than the volume of air drawn by the animal from the plethysmographic chamber. This larger volume of air inside the thorax produces an increase in the plethysmographic chamber pressure, and the reverse occurs during the expiratory phase. The signal from the chamber was processed with computer-installed software (Buxco Biosystem XA v1.1) to calculate several respiratory parameters, including Penh (enhanced pause). This index was obtained by the following formula (Hamelmann et al., 1997) (1):

$$
\text { Penh }=((\text { Te-Rt }) / \text { Rt })(P E P / P I P)
$$

where $\mathrm{Te}=$ expiratory time $(\mathrm{s}), \mathrm{Rt}=$ relaxation time $(\mathrm{s}), \mathrm{PEP}=$ peak expiratory pressure $(\mathrm{cm}$ $\left.\mathrm{H}_{2} \mathrm{O}\right)$, and $\mathrm{PIP}=$ peak inspiratory pressure $\left(\mathrm{cm} \mathrm{H}_{2} \mathrm{O}\right)$. The software was adjusted to only include breaths with a tidal volume of $1 \mathrm{ml}$ or more, with minimal inspiratory time of $0.15 \mathrm{~s}$, maximal inspiratory time of $3 \mathrm{~s}$, and maximal difference between inspiratory and expiratory volumes of $10 \%$. After the guinea pig was placed inside the plethysmographic chamber, a 5min baseline Penh recording was initiated $5 \mathrm{~min}$ later. One minute after OVA or vehicle administration, Penh was recorded at 5 and $10 \mathrm{~min}$, and every $15 \mathrm{~min}$ thereafter. Because Penh was calculated for each breath, adjustments were made to the software to average values from all breaths occurring during $15 \mathrm{~s}$, and then to average these values during the last $5 \mathrm{~min}$ of each period. 


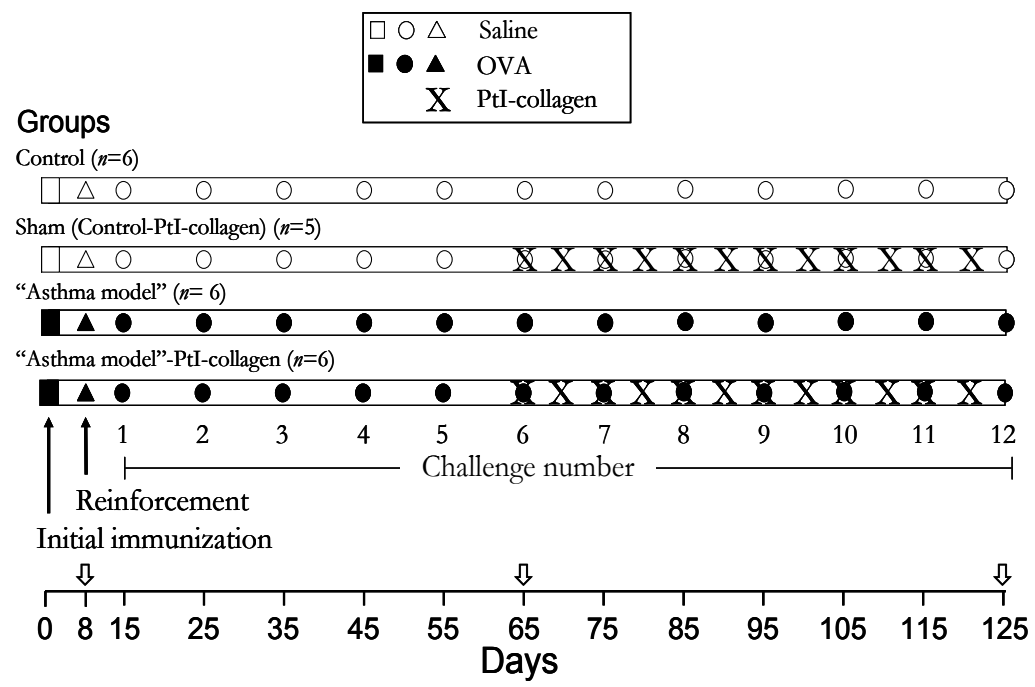

Fig. 1. Experimental design. After initial immunization and reinforcement, guinea pigs received up to twelve antigen challenges. Animals were sacrificed at days 125 after antigeninduced airway hyperresponsiveness was evaluated. $\sqrt{ }=$ antigen-induced airway hyperresponsiveness evaluation day, OVA=ovalbumin, PtI-collagen= polymerized type I collagen.

\subsection{Ptl-collagen treatments}

Some guinea pigs from asthma model group received $0.66 \mathrm{mg} / \mathrm{ml}$ PtI-collagen dispersed in $20 \mathrm{ml}$ of saline for $5 \mathrm{~min}(n=5-6)$. PtI-collagen doses and frequency of administration were selected in accordance to a previous study (Moreno-Alvarez et al., 2010). PtI-collagen aerosols were administrated with an US-1 Bennett nebulizer at a flow rate of $2 \mathrm{ml} / \mathrm{min}$ every 5 days from day 65. PtI-collagen was administrated one hour after OVA when it coincided with the OVA-challenge day. Five guinea pigs from the control group received $0.66 \mathrm{mg} / \mathrm{ml}$ PtI-collagen to constitute the sham group.

\subsection{Antigen-induced airway responsiveness}

Airway responsiveness was evaluated in all groups at day of sensitisation reinforcement and at sixth and twelfth OVA challenges by comparing histamine dose-response curves before and after OVA administration. In guinea pig, histamine aerosol administration induces an all-or-none response (Fig. 2). To avoid receptor desensitization, we administrated non-cumulative doses of histamine from low to high doses (0.01 to $0.1 \mathrm{mg} / \mathrm{ml}$; Fig. 2) after an initial Penh baseline acquisition. The dose-response curve was stopped at the first airway obstructive response in which usually Penh reached three times its baseline level. Each histamine dose was delivered during $1 \mathrm{~min}$, and the average Penh value during the following $5 \mathrm{~min}$ was obtained. The interval between doses was $10 \mathrm{~min}$. Once Penh had returned close to the initial baseline value ( $<50 \%$ increment) (Bazan-Perkins et al., 2004), OVA challenge was administered. The second curve was performed $3 \mathrm{~h}$ after OVA challenge. 


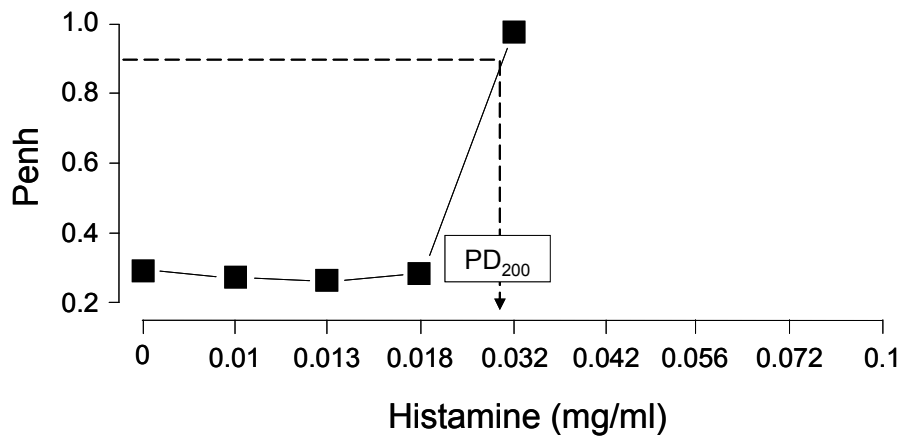

Fig. 2. Dose-response curve to aerosolized histamine. After initial baseline acquisition $(0$ $\mathrm{mg} / \mathrm{ml}$ histamine), guinea pigs received non-cumulative doses to histamine. The arrow shows the provocative dose $200 \%\left(\mathrm{PD}_{200}\right)$, i. e., the interpolated histamine dose that caused a three-fold increase of basal Penh.

\subsection{Cell counts in bronchoalveolar lavage}

One hour after concluding the second histamine curve, and when at least $50 \%$ of baseline Penh was reached (Bazan-Perkins et al., 2004), animals were overdosed with an intraperitoneal injection of pentobarbital sodium $(65 \mathrm{mg} / \mathrm{kg})$ and the trachea was cannulated. Using a syringe, $5 \mathrm{ml}$ of saline solution $\left(37^{\circ} \mathrm{C}\right)$ was introduced through the tracheal tube and gently recovered 1 min later. This procedure was repeated and the recovered fluid was mixed with the first bronchoalveolar lavage fluid. Total recovered fluid was immediately centrifuged for $10 \mathrm{~min}$ at $500 \mathrm{~g}\left(4^{\circ} \mathrm{C}\right)$, the cell pellet was resuspended in 1-ml saline solution, and total cells were counted employing the Kimura stain in a Neubauer haemocytometer. Volume was adjusted to obtain $1 \times 10^{6}$ cells $/ \mathrm{ml}$ and $50 \mu \mathrm{l}$ of this mixture was deposited on a slide stainer $(7120$ Aerospray, Wescor Inc., Logan, Utah, USA) to be stained with Romanowsky stain for differential cell counting. Cell counts were expressed as number of cells per ml of BAL fluid. Cell viability $>80 \%$ was confirmed by Trypan blue exclusion technique in each BAL. All smears were coded, and cells were counted in blind fashion.

\subsection{Conventional histology and automated morphometry analysis}

Left caudal lung lobe was dissected and fixed by manually perfusing $10 \%$ neutral buffered formaldehyde solution via intra-arterial route until lung lobe was exsanguinated. Lung fragments obtained by sagittal cutting were embedded in paraffin, and $4 \mu \mathrm{m}$-thick lung sections were stained with Masson trichrome stain. Surface areas $\left(\mu \mathrm{m}^{2}\right)$ of airways subepithelial mucosa were determined through the use of automated morphometry (Qwin, Leica Microsystems Imaging Solutions, Cambridge, UK). All measurements were conducted in six bronchi chosen at random from each animal, data was adjusted by length of the corresponding basement membrane, and their average was considered the final result. Bronchus was identified by presence or absence of cartilage in airway wall, respectively.

\subsection{Statistical analysis}

Airway responsiveness to histamine was evaluated by means of the provocative dose $200 \%$ $\left(\mathrm{PD}_{200}\right)$, i.e., the interpolated histamine dose that caused a three-fold increase of basal Penh. Changes in histamine responsiveness induced by antigenic challenge was evaluated by the $\mathrm{PD}_{200}$ ratio, i.e., $\mathrm{PD}_{200}$ value observed after OVA challenge divided by $\mathrm{PD}_{200}$ value before 
challenge (Bazan-Perkins et al., 2009). In multiple comparisons, one way or repeated measures ANOVA followed by Tukey or Bonferroni tests were used. Statistical significance was set at two-tailed $P<0.05$. Data in the text and figures are expressed as mean $\pm \mathrm{SE}$.

\section{Results}

Considering that control and sham groups had quite similar results in functional and structural analyses, to avoid excessive data, only control group is shown in the result section.

\subsection{Allergen-induced airway obstructive response in Ptl-collagen treated guinea pigs}

Saline aerosol challenges in control group did not modify Penh basal values. In asthma model guinea pigs, OVA-nebulization at sensitisation reinforcement day did not alter Penh baseline. Nevertheless, since first to twelve OVA-challenges, the asthma model guinea pigs showed a transient Penh increment and maximum responses in the first hour were significantly higher than maximum values in control $(P<0.001 ; n=6$ each group; Fig. 3$)$. PtIcollagen administration in asthma model guinea pigs did not modify maximal Penh responses in comparison with asthma model group but also were higher than control $(P<$ $0.001 ; n=6$ each group; Fig. 3 ).

Baseline Penh values in control animals were similar throughout the study. In asthma model group, a progressive baseline Penh increment that reaches statistical differences at the tenth to the twelfth OVA-challenges in comparison with control group was observed $(P<0.05$; $n=6$ each group; Fig. 4). PtI-collagen treated asthma model guinea pigs also showed a similar pattern of baseline Penh increment and a post hoc analysis demonstrated statistically significant higher Penh values at the eight, tenth $(P<0.05)$ and eleventh $(P<0.01)$ OVA challenges in comparison with control group ( $n=6$ each group; Fig. 4$)$.

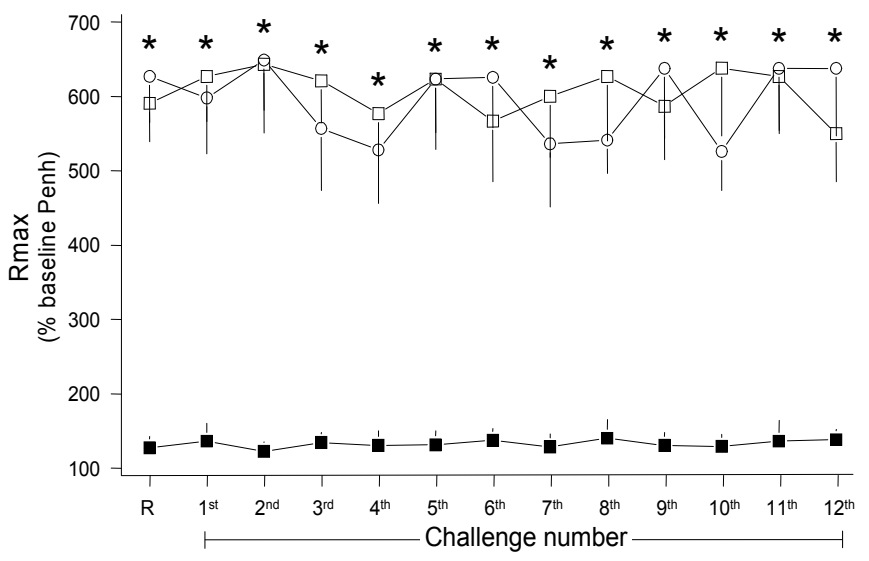

Fig. 3. Airway obstructive responses induced by ovalbumin challenge in PtI-collagen treated allergic guinea pigs. Average of maximum airway obstructive responses (Rmax) induced by ovalbumin (open squares and circles) and saline (close squares) challenges in guinea pigs. PtI-collagen treated guinea pigs are shown in open circles. ${ }^{*}<0.001$ compared with control group (repeated measures ANOVA with Bonferroni's multiple comparisons test). Symbols represent the means $\pm S E$ of $n=6$ of each group. Penh = airway obstruction index. $R=$ sensitisation reinforcement day. 


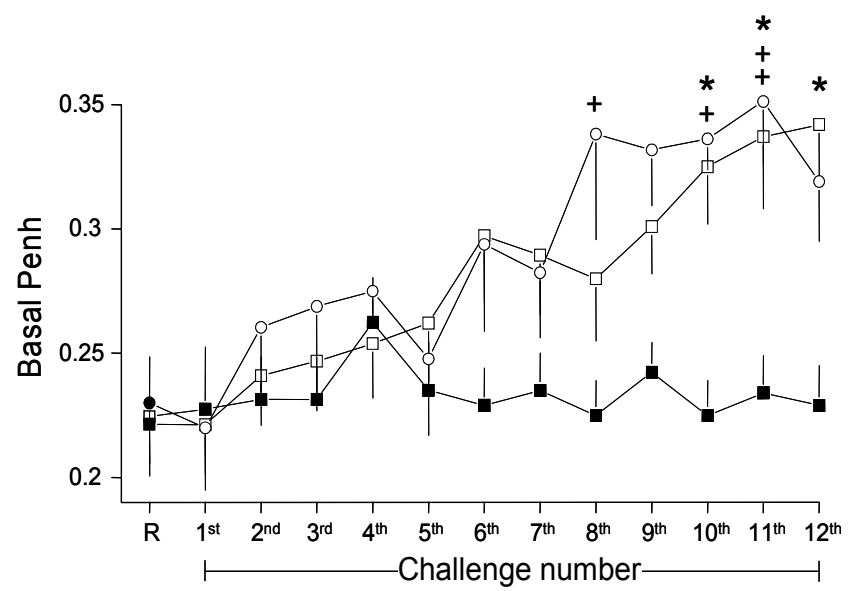

Fig. 4. Baseline airway obstruction index (Penh) changes in PtI-collagen treated guinea pigs. Values of saline (close squares) and ovalbumin (open squares and circle) challenged guinea pigs were obtained at the beginning of each plethysmographic recording and before drug administration. PtI-collagen treated guinea pigs are shown in open circles. ${ }^{*} P<0.05$ asthma model compared with control group, $+P<0.05$ and ${ }^{++} P<0.01$, PtI-collagen treated guinea pigs compared with control groups (repeated measures ANOVA with Bonferroni's multiple comparisons test). Symbols represent the means \pm SE of $n=6$ of each group. $\mathrm{R}=$ sensitisation reinforcement day.

\subsection{Airway responsiveness in Ptl-collagen treated guinea pigs}

$\mathrm{PD}_{200}$ ratio to aerosolised histamine was similar at the sensitisation reinforcement day in control and asthma model groups (Fig. 5). In the sixth OVA challenges, asthma model guinea pigs groups exhibited a significant decrease of histamine $\mathrm{PD}_{200}$ ratio in comparison with control group ( $n=6$ each group; $P<0.05$; Fig. 5). At twelfth OVA-challenge, asthma model guinea pigs showed a significantly $\mathrm{PD}_{200}$ ratio decrement in comparison with control $(n=6$ each group; $P<0.001)$ and asthma model guinea pigs treated with PtI-collagen $(n=6$ each group; $P<0.001$; Fig. 5).

\subsection{Airway structure in Ptl-collagen treated guinea pigs}

Subepithelial mucosa collagen deposit in bronchus, identified with Masson trichrome staining, in asthma models groups was significantly higher than control group $(P<0.001$ when comparing control vs. asthma model; $P<0.05$ when comparing asthma model PtIcollagen treated vs. control guinea pigs; $n=6$ each group; Fig. 6 ). In addition, PtI-collagen asthma model guinea pigs showed a significantly decrement in comparison with asthma model untreated animals $(P<0.001 ; n=6$; Fig. 6$)$.

\subsection{Airway inflammation in Ptl-collagen treated guinea pigs}

Lymphocyte and macrophage numbers in bronchoalveolar lavage fluid were not different among groups (data not shown). Eosinophil and neutrophil increased numbers were statistically significant in comparison with the control group $(P<0.01$; Fig. 7). Likewise, PtIcollagen treatment significantly reduced neutrophil counts in comparison with non-treated PtI-collagen group $(P<0.01 ;$ Fig. 7$)$. 


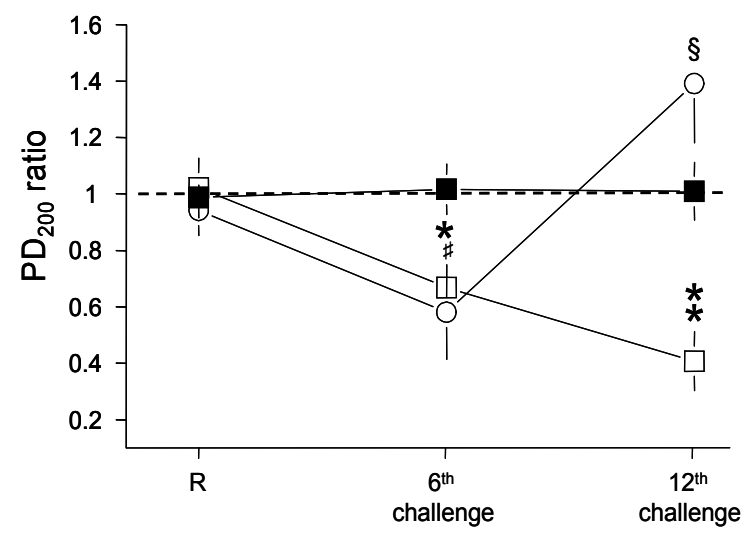

Fig. 5. Airway responsiveness to histamine before and after OVA challenge in PtI-collagen guinea pigs. Symbols correspond to $\mathrm{PD}_{200}$ ratio of control (closed squares) and asthma model guinea pigs (open circles and squares) PtI-collagen treated guinea pigs are shown in open circles. ${ }^{*} P<0.05$ and ${ }^{* *} P<0.01$ asthma group compared with control; ${ }^{*} \mathrm{P}<0.05 \mathrm{PtI}-$ collagen group compared with (repeated measures ANOVA with Bonferroni's multiple comparisons test); $\$ \mathrm{P}<0.01$ untreated asthma group compared with PtI-collagen treated guinea pigs. The line delimited the borderline between hyperresponsiveness (below the line) and hyporresponsiveness (over the line). Symbols represent the means \pm SE of $n=6$ of each group. $\mathrm{R}=$ sensitisation reinforcement day.

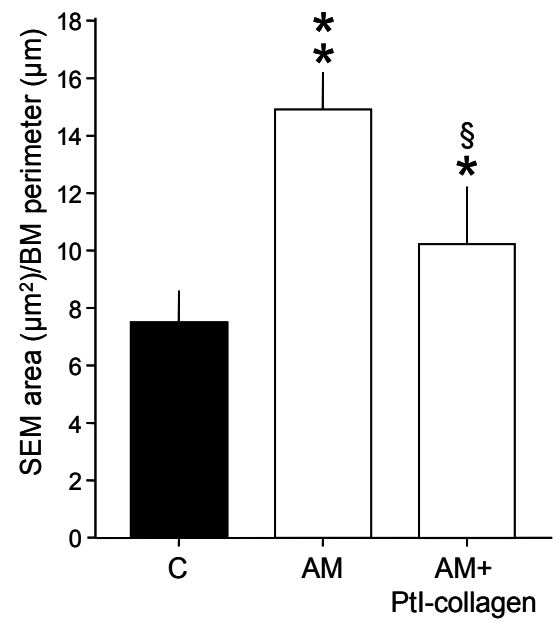

Fig. 6. Subepithelial mucosa changes by PtI-collagen treatment in asthma model. Area of subepithelial mucosa (SEM) of bronchi adjusted by the basement membrane (BM) perimeter, as measured by automated morphometry. Bars and vertical lines are mean \pm SE of $n=6$ in each group. ${ }^{*} P<0.05,{ }^{* *} \mathrm{P}<0.01$ comparing control; $\$ \mathrm{P}<0.05$ when compared untreated asthma guinea pigs with PtI-collagen treated asthma model guinea pigs (one way ANOVA with Tukey's multiple comparisons test). $\mathrm{C}=$ control, $\mathrm{AM}=$ untreated asthma model and $\mathrm{AM}+\mathrm{PtI}$-collagen $=$ asthma model guinea pigs treated with PTI-collagen . 

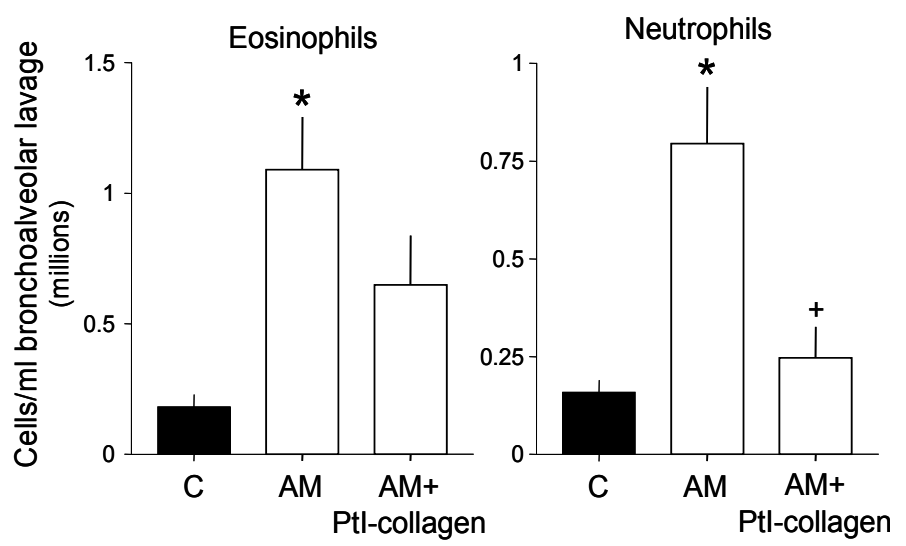

Fig. 7. Bronchoalveolar granulocyte infiltration changes by PtI-collagen treatment in asthma model. Bars and vertical lines are mean \pm SE of $n=6$ in each group. ${ }^{*} P<0.05$ when comparing vs. control, ${ }^{+} P<0.05$ when compared untreated asthma guinea pigs with PtIcollagen treated asthma model guinea pigs (one way ANOVA with Tukey's multiple comparisons test). $\mathrm{C}=$ control, $\mathrm{AM}=$ untreated asthma model and $\mathrm{AM}+\mathrm{PtI}-$ collagen $=$ asthma model guinea pigs treated with PTI-collagen.

\section{Discussion}

PtI-collagen is a biodrug which has shown immunomodulatory, fibrolytic, haemostatic and tissue regeneration properties. In humans, acute and chronic PtI-collagen treatments have been shown not to be genotoxic or to induce a localized hypersensitivity reaction, fibroproliferation (Krotzsch-Gomez et al., 1998), lymphoproliferation, human antiporcine collagen, or anti-collagen-polyvinylpyrrolidone antibodies (Furuzawa-Carballeda et al., 2003). In addition, PtI-collagen is capable to reduce the inflammatory infiltrate (FuruzawaCarballeda et al., 1999; Krotzsch-Gomez et al., 1998), to modulate type I and III collagen turnover (Furuzawa-Carballeda et al., 1999; Furuzawa-Carballeda et al., 2005; FuruzawaCarballeda et al., 2002; Krotzsch-Gomez et al., 1998), and to downregulate the expression level of TNF, interleukin-1 $\beta$ (Furuzawa-Carballeda et al., 2005; Furuzawa-Carballeda et al., 2002; Krotzsch-Gomez et al., 1998), inteleukin-8 (Furuzawa-Carballeda et al., 2002), platelet derived growth factor (Furuzawa-Carballeda et al., 2005; Krotzsch-Gomez et al., 1998), vascular cellular adhesion molecule-1 (Furuzawa-Carballeda et al., 2005; FuruzawaCarballeda et al., 2002), endothelial leukocyte adhesion molecule-1, TGF- $\beta 1$ (FuruzawaCarballeda et al., 2005; Krotzsch-Gomez et al., 1998) and cyclooxygenase-1 (FuruzawaCarballeda et al., 2002). Additionally, tissue inhibitor of metalloproteinase-1 and Fas expression as well as apoptosis are upregulated by this biodrug (Furuzawa-Carballeda et al., 2002). In the current study we have found that PtI-collagen displays anti-inflammatory, antifibrotic and functional properties in a guinea pig asthma model.

Asthma is an airway inflammatory chronic disease that exhibits heterogeneous and variable symptoms derived from airway physiologic abnormalities (Busse \& Lemanske, 2001; Faffe, 2008; Hargreave, In press; Jenkins et al., 2005; Lemanske \& Busse, 2010). A typical inflammatory response in asthma exacerbation is a transient influx of neutrophils, followed by eosinophils accumulation (Fahy, 2009; Taube et al., 2003; Venge, 2010). Airway 
eosinophilia is an important feature of asthma that has been related to airway remodelling (Fahy, 2009; Kariyawasam \& Robinson, 2007; Koerner-Rettberg et al., 2008; Macedo et al., 2009; Passalacqua \& Ciprandi, 2008; Venge, 2010). Neutrophilia in asthma has been associated to the disease severity (Fahy, 2009; Macedo et al., 2009; Wenzel, 2003). Recently, it has been suggested that chronic or unresolved inflammation is the result of the loss of balance of protective mechanisms of the immune system or 'Yin' (tumoricidal) and 'Yang' (tumorigenic) processes (Khatami, 2008; Khatami, 2009; Khatami, 2011); and a chronic allergic process has been shown to facilitate the 'Yang' side of unresolved inflammation (Kathami, 2005). In the guinea pig asthma model, PtI-collagen administration during the acute phase, i.e. from the third to sixth antigen challenges, prevents the infiltration of inflammatory cells and mediators such as neutrophils and TNF (Moreno-Alvarez et al., 2010). In the current study we have shown that PtI-collagen administrated after the acute phase, i.e. from the sixth to twelfth antigen challenges, is capable to revert the neutrophilic inflammation, suggesting that PtI-collagen is able not only to prevent the development of inflammation but also to revert this process.

A consequence of chronic inflammation in the guinea pig asthma model is the accumulation of extracellular matrix components (Bazan-Perkins et al., 2009). It is known that extracellular matrix accumulation in airways is a central component of remodelling that has been detected even in mild childhood asthma (Barbato et al., 2003) and has been associated with asthma severity (Chetta et al., 1997; Wenzel, 2003). Extracellular matrix accumulation is a phenomenon occurring at the sixth antigen challenge in our asthma model (Moreno-Alvarez et al., 2010). In the present study we have observed that PtI-collagen administration, after the sixth antigenic challenge, reverts this accumulation, suggesting that PtI-collagen has important anti-fibrotic properties in the airway wall.

The functional consequences of extracellular matrix accumulation include the residual and permanent airflow limitation (Bazan-Perkins et al., 2009; Sobonya, 1984). In our guinea pig asthma model, a progressive rise in the baseline airway obstruction associated to extracellular matrix component accumulation in airway wall has been observed (BazanPerkins et al., 2009). Nevertheless, our current results show that, although PtI-collagen reverts the accumulation of extracellular matrix components in the airway wall, the baseline airway obstruction rising during the antigenic challenge persists. This suggests that the airway wall thickening in the guinea pig asthma model is not involved in the fixed airflow limitation, and that PtI-collagen has no effect on baseline airflow limitation.

A distinctive physiologic abnormality in asthma is airway hyperresponsiveness (Busse, 2010; Cockcroft et al., 2007; O'Byrne \& Inman, 2003; Sugita et al., 2003). Airway hyperresponsiveness development has been associated to airway inflammation (BazanPerkins et al., 2009; Busse, 2010; Cockcroft \& Davis, 2006; O'Byrne \& Inman, 2003; Sugita et al., 2003) and remodelling (Cockcroft \& Davis, 2006; Cockcroft et al., 2007; O'Byrne \& Inman, 2003). We have previously described in our guinea pig asthma model (Bazan-Perkins et al., 2009) that the number of neutrophils and eosinophils and the extent of extracellular matrix accumulation in airways is related to airway hyperresponsiveness degree. It is noteworthy that PtI-collagen treatment is capable to reduce (Moreno-Alvarez et al., 2010) and revert the neutrophil and extracellular matrix accumulation in airway. Then, our data suggest that neutrophils and fibrosis might be key factors in the development of airway hyperresponsivess in asthma model guinea pig. Finally, PtI-collagen did not modify the maximal airway obstructive responses, suggesting that the modulation of the allergic response is not affected by this biodrug. 


\section{Conclusions}

Our data suggest that PtI-collagen is able to revert the development of neutrophilic infiltration, extracellular matrix deposition and airway hyperresponsiveness in a guinea pig model of chronic asthma. Additionally, it is likely that neutrophils and extracellular matrix component accumulation play significant roles in the development of airway hyperresponsivess in the guinea pig asthma model.

\section{References}

Ascencio, D., Hernandez-Pando, R., Barrios, J., Soriano, R.E., Perez-Guille, B., Villegas, F., Sanz, C.R., Lopez-Corella, E., Carrasco, D. \& Frenk, S. (2004). Experimental induction of heterotopic bone in abdominal implants. Wound Repair and Regeneration, Vol. 12, No. 6, (Nov-Dec, 2003), pp. 643-649, ISSN 1067-1927

Barbato, A., Turato, G., Baraldo, S., Bazzan, E., Calabrese, F., Tura, M., Zuin, R., Beghe, B., Maestrelli, P., Fabbri, L.M. \& Saetta, M. (2003). Airway inflammation in childhood asthma. American Journal of Respiratory and Critical Care Medicine, Vol.168, No.7, (Oct 1, 2002), pp. 798-803, ISSN 1535-4970

Bazan-Perkins, B., Sanchez-Guerrero, E., Vargas, M.H., Martinez-Cordero, E., RamosRamirez, P., Alvarez-Santos, M., Hiriart, G., Gaxiola, M. \& Hernandez-Pando, R. (2009). Beta1-integrins shedding in a guinea-pig model of chronic asthma with remodelled airways. Clinical and Experimental Allergy, Vol. 39, No. 5, (May, 2009), pp. 740-751, ISSN 1365-2222

Bazan-Perkins, B., Vargas, M.H., Sanchez-Guerrero, E., Chavez, J. \& Montano, L.M. (2004). Spontaneous changes in guinea-pig respiratory pattern during barometric plethysmography: role of catecholamines and nitric oxide. Experimental Physiology, Vol. 89, No. 5, (Sep, 2003), pp. 623-628, ISSN 0958-0670

Broekema, M., Timens, W., Vonk, J.M., Volbeda, F., Lodewijk, M.E., Hylkema, M.N., Ten Hacken, N.H. \& Postma, D.S. (2011). Persisting Remodeling and Less Airway Wall Eosinophil Activation in Complete Remission of Asthma. American Journal of Respiratory and Critical Care Medicine, (Sep 2), pp. 1535-4970 ISSN 1073-449X

Busse, W.W. (2010). The relationship of airway hyperresponsiveness and airway inflammation: Airway hyperresponsiveness in asthma: its measurement and clinical significance. Chest, Vol. 138, No. 2 Suppl, (August 2010), pp. 4S-10S, ISSN 1931-3543

Busse, W.W. \& Lemanske, R.F., Jr. (2001). Asthma. The New England Journal of Medicine, Vol. 344, No. 5, (Feb 1, 2001), pp. 350-362, ISSN 0028-4793

Cervantes-Sanchez, C.R., Olaya, E., Testas, M., Garcia-Lopez, N., Coste, G., Arrellin, G., Luna, A. \& Krotzsch, F.E. (2003). Collagen-PVP, a collagen synthesis modulator, decreases intraperitoneal adhesions. The Journal of Surgical Research, Vol. 110, No. 1, (Mar, 2003), pp. 207-210, ISSN 0022- 4804

Cockcroft, D.W. \& Davis, B.E. (2006). Mechanisms of airway hyperresponsiveness. The Journal of Allergy and Clinical Immunology, Vol. 118, No. 3, (Sep, 2006), pp. 551-559 ISSN 0091-6749

Cockcroft, D.W., Hargreave, F.E., O'Byrne, P.M. \& Boulet, L.P. (2007). Understanding allergic asthma from allergen inhalation tests. Canadian Respiratory Journal, Vol. 14, No. 7, (Oct, 2007), pp. 414-418, ISSN 1198-2241. 
Chetta, A., Foresi, A., Del Donno, M., Bertorelli, G., Pesci, A. \& Olivieri, D. (1997). Airways remodeling is a distinctive feature of asthma and is related to severity of disease. Chest, Vol. 111, No .4, (Apr, 1997), pp. 852-857, ISSN 0012-3692

Chimal-Monroy, J., Bravo-Ruiz, T., Furuzawa-Carballeda, G.J., Lira, J.M., de la Cruz, J.C., Almazan, A., Krotzsch-Gomez, F.E., Arrellin, G. \& Diaz de Leon, L. (1998). Collagen-PVP accelerates new bone formation of experimentally induced bone defects in rat skull and promotes the expression of osteopontin and SPARC during bone repair of rat femora fractures. Annals of the New York Academy of Sciences, Vol. 857, (Oct 23,1998), pp. 232-236, ISSN 0077-8923

Faffe, D.S. (2008). Asthma: where is it going? Brazilian Journal of Medical and Biological Research $=$ Revista Brasileira de Pesquisas Medicas e Biológicas, Vol.41, No.9, (September, 2008), pp. 739-749, ISSN 1414-431X

Fahy, J.V. (2009). Eosinophilic and neutrophilic inflammation in asthma: insights from clinical studies. Proceedings of the American Thoracic Society, Vol. 6, No. 3, (May 1, 2009), pp. 256-259, ISSN 1546-3222

Furuzawa-Carballeda, J., Alcocer-Varela, J. \& Diaz de Leon, L. (1999). Collagen-PVP decreases collagen turnover in synovial tissue cultures from rheumatoid arthritis patients. Annals of the New York Academy of Sciences, Vol. 878, (Jun 30, 1999), pp. 598602, ISSN 0077-8923

Furuzawa-Carballeda, J., Krotzsch, E., Barile-Fabris, L., Alcala, M. \& Espinosa-Morales, R. (2005). Subcutaneous administration of collagen-polyvinylpyrrolidone down regulates IL-1beta, TNF-alpha, TGF-beta1, ELAM-1 and VCAM-1 expression in scleroderma skin lesions. Clinical and Experimental Dermatology, Vol. 30, No. 1, (Jan, 005), pp. 83-86, ISSN 0307-6938

Furuzawa-Carballeda, J., Rodriquez-Calderon, R., Diaz de Leon, L. \& Alcocer-Varela, J. (2002). Mediators of inflammation are down-regulated while apoptosis is upregulated in rheumatoid arthritis synovial tissue by polymerized collagen. Clinical and Experimental Immunology, Vol. 130, No. 1, (Oct, 2001), pp. 140-149, ISSN 00099104

Furuzawa-Carballeda, J., Rojas, E., Valverde, M., Castillo, I., Diaz de Leon, L. \& Krotzsch, E. (2003). Cellular and humoral responses to collagen-polyvinylpyrrolidone administered during short and long periods in humans. Canadian Journal of Physiology and Pharmacology, Vol. 81, No. 11, (Nov, 2002), pp. 1029-1035, ISSN 00084212

Hamelmann, E., Schwarze, J., Takeda, K., Oshiba, A., Larsen, G.L., Irvin, C.G. \& Gelfand, E.W. (1997). Noninvasive measurement of airway responsiveness in allergic mice using barometric plethysmography. American Journal of Respiratory and Critical Care Medicine, Vol. 156, No. 3 Pt 1, (Sep, 1997), pp. 766-775, ISSN 1073-449X

Hargreave, F.E. (In press). Asthma is not a syndrome. The Journal of Allergy and Clinical Immunology, (Jun 17, 2011), pp. ISSN 1097-6825

Janson, C. (2010). The importance of airway remodelling in the natural course of asthma. The Clinical Respiratory Journal, Vol. 4 Suppl 1, (May, 2010), pp. 28-34, ISSN 1752$699 X$

Jeffery, P.K., Laitinen, A. \& Venge, P. (2000). Biopsy markers of airway inflammation and remodelling. Respiratory Medicine, Vol.94 Suppl F, (Oct, 2000), pp. S9-15, ISSN 09546111 
Jenkins, C.R., Thompson, P.J., Gibson, P.G. \& Wood-Baker, R. (2005). Distinguishing asthma and chronic obstructive pulmonary disease: why, why not and how? The Medical Journal of Australia, Vol. 183, No. 1 Suppl, (Jul 4, 2005), pp. S35-37, 0025-729X

Kariyawasam, H.H. \& Robinson, D.S. (2007). The role of eosinophils in airway tissue remodelling in asthma. Current Opinion in Immunology, Vol. 19, No. 6, (Dec, 2007), pp. 681-686, ISSN 0952-7915

Kathami, M. (2005) Developmental phases of inflammation-induced massive lymphoid hyperplasia and extensive changes in epithelium in an experimental model of allergy: implications for a direct link between inflammation and carcinogenesis. American Journal of Therapeutics, Vol. 12, No. 2, (Mar-Apr 2005), pp. 117-126, ISSN $1075-2765$

Khatami, M. (2008) 'Yin and Yang' in inflammation: duality in innate immune cell function and tumorigenesis. Expert Opinion on Biological Therapy, Vol. 8, No. 10, (Oct, 2008), pp. 1461-1472, ISSN 1471-2598

Khatami, M. (2009). Inflammation, aging, and cancer: tumoricidal versus tumorigenesis of immunity: a common denominator mapping chronic diseases. Cellular Biochemistry and Biophysics, Vol. 55, No. 2, (Aug 2009), pp. 55-79, ISSN 10859195

Khatami, M. (2011). Unresolved inflammation: 'immune tsunami' or erosion of integrity in immune-privileged and immune-responsive tissues and acute and chronic inflammatory diseases or cancer. Expert Opinion on Biological Therapy, (Jun, 2011), in press, ISSN 1471-2598

Kim, S.R. \& Rhee, Y.K. (2010). Overlap Between Asthma and COPD: Where the Two Diseases Converge. Allergy, Asthma \& Immunology Research, Vol. 2, No. 4, (Oct, 2010), pp. 209-214, ISSN 2092-7363

Koerner-Rettberg, C., Doths, S., Stroet, A. \& Schwarze, J. (2008). Reduced lung function in a chronic asthma model is associated with prolonged inflammation, but independent of peribronchial fibrosis. PloS one, Vol. 3, No. 2, pp. e1575, ISSN 1932-6203

Krotzsch-Gomez, F.E., Furuzawa-Carballeda, J., Reyes-Marquez, R., Quiroz-Hernandez, E. \& Diaz de Leon, L. (1998). Cytokine expression is downregulated by collagenpolyvinylpyrrolidone in hypertrophic scars. The Journal of Investigative Dermatology, Vol. 111, No. 5, (Nov, 1998), pp. 828-834, ISSN 0022-202X

Lemanske, R.F., Jr. \& Busse, W.W. (2010). Asthma: clinical expression and molecular mechanisms. The Journal of Allergy and Clinical Immunology, Vol. 125, No. 2 Suppl 2, (February 2010), pp. S95-S102, ISSN 1097-6825

Macedo, P., Hew, M., Torrego, A., Jouneau, S., Oates, T., Durham, A. \& Chung, K.F. (2009). Inflammatory biomarkers in airways of patients with severe asthma compared with non-severe asthma. Clinical and Experimental Allergy, Vol. 39, No. 11, (Nov, 2009), pp. 1668-1676, ISSN 1365-2222

Moreno-Alvarez, P., Sanchez-Guerrero, E., Martinez-Cordero, E., Hernandez-Pando, R., Campos, M.G., Cetina, L. \& Bazan-Perkins, B. (2010). Aerosolized polymerized type I collagen reduces airway inflammation and remodelling in a guinea pig model of allergic asthma. Lung, Vol. 188, No. 2, (Apr, 2010), pp. 97-105, ISSN 1432-1750. 
O'Byrne, P.M. \& Inman, M.D. (2003). Airway hyperresponsiveness. Chest, Vol. 123, No. 3 Suppl, (Mar, 2003), pp. 411S-416S, ISSN 0012-3692

Olmos-Zuniga, J.R., Hernandez-Jimenez, C., Diaz-Martinez, E., Jasso-Victoria, R., SotresVega, A., Gaxiola-Gaxiola, M.O., Villalba-Caloca, J., Baltazares-Lipp, M., SantillanDoherty, P. \& Santibanez-Salgado, J.A. (2007). Wound healing modulators in a tracheoplasty canine model. Journal of Investigative Surgery, Vol.20, No.6, (Nov-Dec, 2007), pp. 333-338, ISSN 0894-1939.

Passalacqua, G. \& Ciprandi, G. (2008). Allergy and the lung. Clinical and Experimental Immunology, Vol. 153 Suppl 1, (Sep, 2008), pp. 12-16, ISSN 1365-2249.

Salerno, F.G., Barbaro, M.P., Toungoussova, O., Carpagnano, E., Guido, P. \& Spanevello, A. (2009). The extracellular matrix of the lung and airway responsiveness in asthma. Monaldi archives for chest disease = Archivio Monaldi per le malattie del torace / Fondazione clinica del lavoro, IRCCS [and] Istituto di clinica tisiologica e malattie apparato respiratorio, Universita di Napoli, Secondo ateneo, Vol. 71, No.1, (Mar, 2009), pp. 27-30, ISSN 1122-0643.

Sanchez-Pozos, K., Lee-Montiel, F., Perez-Villalva, R., Uribe, N., Gamba, G., Bazan-Perkins, B. \& Bobadilla, N.A. (2010). Polymerized type I collagen reduces chronic cyclosporine nephrotoxicity. Nephrology and Dialysis Transplant, Vol. 25, No. 7, (Jul, 2010), pp. 2150-2158, ISSN 1460-2385

Sobonya, R.E. (1984). Quantitative structural alterations in long-standing allergic asthma. The American Review of Respiratory Disease, Vol. 130, No. 2, (Aug, 1984), pp. 289-292, ISSN 0003-0805

Sugita, M., Kuribayashi, K., Nakagomi, T., Miyata, S., Matsuyama, T. \& Kitada, O. (2003). Allergic bronchial asthma: airway inflammation and hyperresponsiveness. Internal Medicine (Tokyo, Japan), Vol. 42, No. 8, (Aug, 2003), pp. 636-643, ISSN 0918-2918.

Taube, C., Dakhama, A., Rha, Y.H., Takeda, K., Joetham, A., Park, J.W., Balhorn, A., Takai, T., Poch, K.R., Nick, J.A. \& Gelfand, E.W. (2003). Transient neutrophil infiltration after allergen challenge is dependent on specific antibodies and FC gamma III receptors. Journal of Immunology, Vol. 170, No.8, (Apr 15, 2003), pp. 4301-4309, ISSN 0022-1767.

Venge, P. (2010). The eosinophil and airway remodelling in asthma. The Clinical Respiratory Journal, Vol. 4 Suppl 1, No. 2010, (May, 2010), pp. 15-19, ISSN1752-699X

Wenzel, S. (2003). Mechanisms of severe asthma. Clinical and Experimental Allergy, Vol. 33, No.12, (Dec, 2003), pp. 1622-1628, ISSN 0954-7894. 


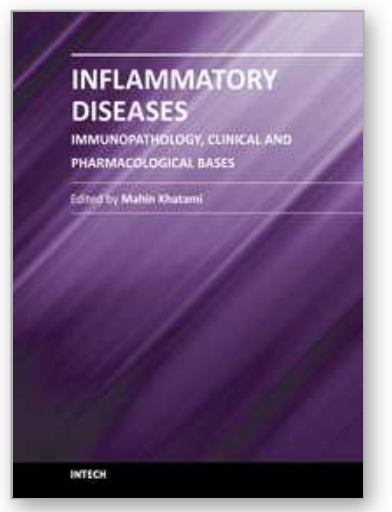

\author{
Inflammatory Diseases - Immunopathology, Clinical and \\ Pharmacological Bases \\ Edited by Dr Mahin Khatami
}

ISBN 978-953-307-911-0

Hard cover, 396 pages

Publisher InTech

Published online 10, February, 2012

Published in print edition February, 2012

This book is a collection of comprehensive reviews contributed by experts in the diverse fields of acute and chronic inflammatory diseases, with emphasis on current pharmacological and diagnostic options. Interested professionals are also encouraged to review the contributions made by experts in a second related book entitled "Inflammation, Chronic Diseases and Cancer"; it deals with immunobiology, clinical reviews, and perspectives of the mechanisms of immune inflammatory responses that are involved in alterations of immune dynamics during the genesis, progression and manifestation of a number of inflammatory diseases and cancers, as well as perspectives for diagnosis, and treatment or prevention of these disabling and potentially preventable diseases, particularly for the growing population of older adults around the globe.

\title{
How to reference
}

In order to correctly reference this scholarly work, feel free to copy and paste the following:

Blanca Bazán-Perkins, Maria G. Campos and Edgar Sánchez-Guerrero (2012). Polymerized Type I Collagen Reverts Airway Hyperresponsiveness and Fibrosis in a Guinea Pig Asthma Model, Inflammatory Diseases Immunopathology, Clinical and Pharmacological Bases, Dr Mahin Khatami (Ed.), ISBN: 978-953-307-911-0, InTech, Available from: http://www.intechopen.com/books/inflammatory-diseases-immunopathology-clinicaland-pharmacological-bases/polymerized-type-i-collagen-reverts-airway-hyperresponsiveness-and-fibrosis-ina-guinea-pig-asthma-m

\section{INTECH}

open science | open minds

\section{InTech Europe}

University Campus STeP Ri

Slavka Krautzeka 83/A

51000 Rijeka, Croatia

Phone: +385 (51) 770447

Fax: +385 (51) 686166

www.intechopen.com

\section{InTech China}

Unit 405, Office Block, Hotel Equatorial Shanghai

No.65, Yan An Road (West), Shanghai, 200040, China

中国上海市延安西路65号上海国际贵都大饭店办公楼 405 单元

Phone: +86-21-62489820

Fax: $+86-21-62489821$ 
(C) 2012 The Author(s). Licensee IntechOpen. This is an open access article distributed under the terms of the Creative Commons Attribution 3.0 License, which permits unrestricted use, distribution, and reproduction in any medium, provided the original work is properly cited. 